\title{
Coordinated and Tailored Work Rehabilitation: A Randomized Controlled Trial with Economic Evaluation Undertaken with Workers on Sick Leave Due to Musculoskeletal Disorders
}

\author{
Ute Bültmann · David Sherson · Jens Olsen • \\ Carl Lysbeck Hansen · Thomas Lund • \\ Jørgen Kilsgaard
}

Published online: 24 January 2009

(c) The Author(s) 2009. This article is published with open access at Springerlink.com

\begin{abstract}
Introduction In Denmark, the magnitude and impact of work disability on the individual worker and society has prompted the development of a new "coordinated and tailored work rehabilitation" (CTWR) approach. The aim of this study was to compare the effects of CTWR with conventional case management (CCM) on return-towork of workers on sick leave due to musculoskeletal disorders (MSDs). Methods The study was a randomized controlled trial with economic evaluation undertaken with workers on sick leave for 4-12 weeks due to MSDs. CTWR consists of a work disability screening by an interdisciplinary team followed by the collaborative development of a RTW plan. The primary outcome variable was registered cumulative sickness absence hours during 12 months follow-up. Secondary outcomes were work status as well as pain intensity and functional disability, measured at baseline, 3 and 12 months follow-up. The economic evaluation (intervention costs, productivity
\end{abstract}

U. Bültmann ( $\square)$

Department of Health Sciences, Section of Social Medicine,

Work \& Health, University Medical Center Groningen,

A. Deusinglaan 1, Building 3217, Room 605,

9713 AV Groningen, The Netherlands

e-mail: u.bultmann@med.umcg.nl

U. Bültmann

Department of Health Sciences, University of Groningen,

Groningen, The Netherlands

U. Bültmann

National Research Centre for the Working Environment,

Copenhagen, Denmark

D. Sherson · C. L. Hansen

Department of Occupational and Environmental Medicine,

Vejle Hospital, Vejle, Denmark loss, and health care utilization costs) was based on administrative data derived from national registries. Results For the time intervals 0-6 months, 6-12 months, and the entire follow-up period, the number of sickness absence hours was significantly lower in the CTWR group as compared to the control group. The total costs saved in CTWR participants compared to controls were estimated at US \$ 1,366 per person at 6 months follow-up and US \$ 10,666 per person at 12 months follow-up. Conclusions Workers on sick leave for 4-12 weeks due to MSD who underwent "CTWR" by an interdisciplinary team had fewer sickness absence hours than controls. The economic evaluation showed that-in terms of productivity lossCTWR seems to be cost saving for the society.

Keywords Musculoskeletal disorder - Sickness absence · Interdisciplinary team · Return-to-work .

Coordinated rehabilitation

\author{
J. Olsen \\ Centre for Applied Health Services Research and Technology \\ Assessment, University of Southern Denmark, Odense, Denmark \\ T. Lund \\ Department of Employment and Integration, The Danish \\ National Centre for Social Research, Copenhagen, Denmark \\ J. Kilsgaard \\ Department of Development and Labor Market, \\ Vejle County, Vejle, Denmark \\ J. Kilsgaard \\ KIApro, Copenhagen, Denmark
}




\section{Introduction}

Long-term sick leave due to musculoskeletal disorders (MSDs) has considerable social and economic consequences for workers and their families, employers, and society. It tends to marginalize the worker from the workplace [1] and is associated with risk of future disability pension [2-5]. In Denmark, total annual sick leave is approximately 150,000 full-time absences, i.e., about 5\% of the workforce [6]. Thus both, the reduction of long-term sick leave and the retention of employees in the workforce are high on the political agenda.

During the past decade, many studies have shown that work disability is a complex, multifactorial problem. The worker/patient, the employer, the healthcare provider, and the insurer, are all involved in the work disability process, often in complex interplays [7-10]. Also, the process of return to work (RTW) following ill health has a multifactorial nature, including complex interactions between (1) biological, psychological, and social factors as well as (2) different "systems", such as the personal, workplace, health care and insurance system [7, 9, 11-13]. Moreover, work disability and RTW processes and practices have to be understood and appreciated within the specific administrative and jurisdictional context $[7,11,14]$.

In Denmark, the growing awareness of the magnitude and impact of work disability on the individual worker and society, has led to the recognition that there is little information about "successful" RTW processes and practices for workers absent from work due to MSDs. The absence of this information and the need for effective RTW measures has prompted the development of a new "coordinated and tailored work rehabilitation" (CTWR) approach, based on a Canadian multidisciplinary work rehabilitation program (i.e., the Sherbrooke model by Loisel et al.) [7, 15-17]. Loisel et al. [16] found that the combination of an occupational intervention and a clinical rehabilitation intervention was effective on disability and RTW. The Sherbrooke model has inspired other similar studies outside Canada, like the study on multidisciplinary rehabilitation for subacute low back pain in The Netherlands [18-20]. Due to country-specific characteristics of health care systems, legislation, and case management of sick-listed workers, the underlying intervention models and previous findings are not directly translatable to other countries. It is important, however, to undertake intervention studies in different contexts to see how reliable and generalizable results are.

The aim of the new "CTWR" approach is to reduce sick leave and to facilitate a safe, healthy, and sustainable RTW in Danish workers. In brief, CTWR includes an interdisciplinary team, whose multi-professional competencies are used to formulate a coordinated, tailored, and action- oriented RTW plan based on a multidisciplinary assessment. CTWR differs from conventional case management with its focus on collaboration between the primary and secondary health care sectors, the social sector, and the workplace.

Thus, the main objective of this study was to compare the effect of CTWR with conventional case management (CCM, i.e., control treatment) on return-to-work of workers on sick leave for 4-12 weeks due to MSDs. The hypothesis was that workers in the CTWR "intervention" group would have fewer sickness absence hours during follow-up than those in the CCM control group. In addition, an economic evaluation was conducted, in which intervention costs, productivity loss and costs for health care utilization were compared between the CTWR group and CCM control group.

\section{Methods}

Design and Procedure

The study was a randomized controlled trial, undertaken at the Department of Development and Labor Market at Vejle County (Denmark). Participants were recruited between April 2004 and April 2005. Workers on sick leave for at least 4 weeks were invited to an information meeting at one of the four participating municipalities Vejle, Kolding, Egtved, and Give (total population of about $n=150,000$ ). Written informed consent was obtained from all participants. Study eligibility required participants to be absent from work for 4-12 weeks, to have a reimbursement request indicating low back pain (LBP) or MSD as the main cause of sick leave, and to be between 18 and 65 years of age. We excluded workers with mental health disorders, alcohol or drug addiction as well as those who were pregnant, had quit their job or had been fired before randomization. Understanding and speaking Danish was also required. In the first 6 months, we included workers with LBP. Later, workers with other MSDs were also included to obtain a sufficient number of study subjects. We have no particular explanation for our recruitment problem as the pilot study suggested a sufficient supply of suitable LBP subjects.

The study was designed to detect a $20 \%$ difference in cumulated sickness absence hours with a power of $90 \%$ at $\alpha=0.05$. To achieve this, a sample size of 200 workers (100 per group) was required. During an information meeting at the municipality, potential participants received detailed written and oral information on the project. If an eligible worker wanted to participate, he/she was asked to complete an informed consent form and the baseline questionnaire. A randomization protocol without 
stratification was computer-generated prior to the start of the study and was undertaken by an independent IT assistant. After informed consent, participants were randomly allocated to either CTWR or CCM. The allocation was concealed from the researchers responsible for data analysis. Concurrent to inclusion of workers in the study, the employers of the sick-listed workers were informed about the project.

Data was collected from two sources: self-report questionnaires and administrative data from three national registries. At the start of the study, all participants completed a baseline questionnaire that provided information on sociodemographic factors and baseline outcome values. Outcome was further assessed at 3 and 12 months follow-up.

\section{Jurisdictional Context: The Danish Sick Leave Policy}

In Denmark, the public sickness benefit scheme covers wage earners, self-employed, and unemployed persons [21]. No distinction is made between sickness absences due to work-related or non-work-related causes. In the case of wage earners, compensation is paid through the employer who can apply for a refund from the municipality covering sickness absence after the first 2 weeks. Full wage compensation up to an amount that equals the maximum unemployment benefit is refunded. Benefits can normally be received for a maximum of 52 weeks during an 18 months period. Municipalities are obliged to make a follow-up assessment of all sickness benefit cases within 8 weeks after the first day of work incapacity and thereafter every 8th week. The follow-up assessment should be based on updated medical, social, and vocational information. The sick-listed individual can be called in for a personal interview if the case manager considers this necessary. The assessment should be carried out in cooperation with relevant agents such as the employer, medical experts, vocational rehabilitation institutions, and unions. At the interview, the case manager may advise the sick-listed person about contacting the employer, possibilities for partial work resumption, modification of job demands, job counseling, and possibilities for vocational rehabilitation. For a detailed description of the Danish sick leave policy see Høgelund and Holm [21].

Intervention: Coordinated and Tailored Work Rehabilitation (CTWR)

CTWR consists of two main components: (1) a work disability screening: a systematic, multidisciplinary assessment of disability and functioning as well as the identification of barriers for RTW (based on the program developed by Loisel et al. [7, 16, 22]); and (2) the formulation and implementation of a coordinated, tailored and action-oriented work rehabilitation plan collaboratively developed by an interdisciplinary team using a feedbackguided approach. This approach develops a dynamic loop where evaluations and interventions are periodically re-adjusted as new information is obtained. Theoretical inspiration was derived from computer science developments concerning feedback-guided dynamic loop scheduling. The interdisciplinary team consists of an occupational physician, an occupational physiotherapist, a chiropractor, a psychologist, and a social worker who has the role of case worker establishing and maintaining contact with the workplace and the municipal case manager.

CTWR begins after 4-12 weeks of sick leave with a systematic work disability screening and the identification of barriers for RTW. The matrix for work disability screening is based on the ICF (The International Classification of Functioning, Disability and Health, WHO; www.who.int/classifications/icf/site/icftemplate.cfm) and the biopsychosocial model of functioning [23]. The theoretical framework of CTWR builds upon two sociopsychological concepts: readiness for RTW [24] and selfefficacy [25]. Involvement of the workplace and other major stakeholders are also key elements. Approximately 1 week after inclusion, the CTWR participant is invited to the systematic, multidisciplinary work disability screening, where he/she consecutively sees the occupational physician (medical assessment), the chiropractor (biomechanical assessment), the occupational physiotherapist (work-related assessment), and the psychologist (psychological assessment). The screening takes about $2 \mathrm{~h}, 30 \mathrm{~min}$ per discipline, and is followed by an interdisciplinary team conference of another $30 \mathrm{~min}$, with case worker participation. During the team conferences, new cases are presented and the need for additional information is discussed. Based on the work disability screening and the identified barriers for RTW, a coordinated, tailored and action-oriented work rehabilitation plan is collaboratively developed. This plan is then discussed with the sick-listed worker, who can comment on it. If accepted by all parties, the plan is entered into an electronic journal and sent to the municipality as well as to the sick-listed worker's general practitioner. Three areas of action can be distinguished in the RTW plan: (1) action directed at the absent worker; (2) action directed at the workplace (e.g., workplace accommodation); and (3) action directed at barriers in the environment. The implementation of the RTW plan is a dynamic process with continuous feedback among the sicklisted worker, the interdisciplinary team, the workplace, and major stakeholders. The CTWR is no longer than 3 months. 
Control Treatment: Conventional Case Management (CCM)

In the present study, the conventional case management (CCM) controls received the same information about the study and the same (follow-up) questionnaires as the CTWR participants. However, CCM controls were not offered any additional assessment or action. Accordingly, CCM controls received the conventional case management as provided by the municipality.

\section{Outcomes}

\section{Primary Outcome}

Administrative data on cumulative sickness absence hours was the primary outcome in this study. The time intervals for the cumulated sickness absence hours were 0-3 months, 3-6 months, 6-12 months as well as 0-6 months and 0-12 months. Administrative data on sickness absence hours was obtained from the Danish National Health Insurance Service Registry and provided by Vejle County without knowledge of workers allocation to CTWR or CCM.

\section{Secondary Outcomes}

Work status, pain intensity, and functional disability were our secondary outcomes. Information on the work status (i.e., RTW, full-time sick leave or part-time sick leave) at 3, 6, and 12 months was obtained from the Danish National Health Insurance Service Registry. Information on pain intensity and functional disability was obtained by selfreport questionnaires at 3 and 12 months follow-up. Pain intensity was measured by two items from the ÖMPSQ [26] on a 10 -point numerical rating scale $(0=$ no pain to $10=$ worst possible pain). Participants were asked to indicate their level of perceived pain during the past week and on average in the past month. Functional disability was measured with the Danish version of the Oswestry Low Back Pain Disability Questionnaire [27, 28], with $10 \mathrm{sec}-$ tions referring to activities of daily living. The individual responses were summed up; scores ranged from 0 (severe functional disability) to 100 (no functional disability).

Initiatives and Actions for RTW During the First

3 Months of Follow-up

To get an overview about the initiatives and actions for RTW during the 3 months following baseline, CTWR participants and CCM controls were asked to provide information about their disability management activities, such as whether they had seen a general practitioner or had participated in a roundtable discussion. A roundtable discussion includes the sick-listed worker, a health professional, a municipal case worker as well as representatives from the workplace and the local union. All participants have equal status. A roundtable discussion is often initiated by a municipal case worker and might thus involve either CTWR study subjects or CCM controls. The purpose of a roundtable discussion is to develop a specific and feasible RTW plan.

\section{Economic Evaluation}

The economic evaluation was performed as a cost-benefitanalysis, applying a societal perspective. In the analysis, the incremental costs between the CTWR group and the CCM group were estimated. The analyses were based on administrative data. Cumulative sickness absence hours were obtained from the Danish National Health Insurance Service. Information about consultations and costs of primary health care utilization, outpatient treatment, hospitalization, and prescribed medication was collected from three registries: the Danish National Health Insurance Service Registry, the Danish National Patient Registry, and the Danish National Prescription Registry.

The analysis comprised direct intervention costs for CTWR, possible saved costs due to reduced production loss (i.e., reduced productivity costs), and possible differences in costs between the CTWR and CCM groups for primary and secondary health care treatment as well as prescribed medication. The estimation of the direct intervention costs was based on an accounts analysis of the interdisciplinary team. The estimation of productivity costs was based on the human capital approach with production per hour being valued as the gross wage per hour (including employment overhead and benefits), i.e., paid employment was valued by the gross earnings. Six different wage levels were applied depending on employment group (Table LON02, www.statistikbanken.dk, cited: September 2006). The costs for primary health care utilization, outpatient treatment, hospitalization, and prescribed medication were estimated from register data and valued by fees (primary health care), charges (secondary health care) and market prices (prescribed medicine). The costs of health care utilization were compared between the CTWR and CCM groups for the entire follow-up period of 12 months. In the cost-benefit-analysis, the incremental costs between the CTWR and CCM groups were estimated and the intervention benefits were incorporated into the differences in productivity costs. In this analysis, only working hours were valued, i.e., other benefits/effects (e.g., better ability to engage in leisure activities) were not included in the productivity costs and were not valued. Furthermore, cost-effectiveness analyses (i.e., intervention costs and treatment costs at outpatient clinics per averted 
absence day) and one-way sensitivity analyses were undertaken.

\section{Statistical Analysis}

The analysis was conducted on an intention-to-treat basis. Univariate statistics (means, standard deviations, frequency counts) were used to describe participants for the total study population and by group (CTWR or CCM) in terms of their baseline socio-demographics and health outcomes. Differences in baseline characteristics between CTWR and CCM groups were tested with $t$-tests, $\chi^{2}$ tests, and Mann Whitney $U$ tests for variables that were not normally distributed.

Because our primary outcome measure "cumulative sickness absence hours" was not normally distributed for the five time intervals, Mann Whitney $U$ tests were used to examine differences between the groups. Administrative sickness absence data were available for all participants. Due to loss to follow-up, data on the secondary outcome measures, pain intensity and functional disability as assessed by questionnaire, were not available for all participants. For the economic evaluation, registry data were available for all participants. Differences between the
CTWR and CCM group were tested using $t$-tests (for normally distributed variables) or the Wilcoxon test (for variables not normally distributed). All data were entered by two individuals and compared to ensure accuracy. Analysis was undertaken using SPSS 14 (SPSS Inc., Chicago, IL) and SAS 9.1.

\section{Results}

\section{Study Population}

A total of 119 workers was included and randomized to CTWR $(n=68)$ or CCM $(n=51)$. Despite the promising results of a pilot study, it was not possible to recruit the required sample size of 100 workers per group during the one-year inclusion period. After randomization, six participants (CTWR $n=2$ and CCM $n=4$ ) withdrew their informed consent because of misunderstanding the project, pregnancy, moving out of the municipality, perceived language barriers or being included in another program. This resulted in 66 CTWR participants and 47 CCM controls for the register-based analyses. All 66 participants allocated to CTWR underwent the multidisciplinary

Fig. 1 Participant flow diagram

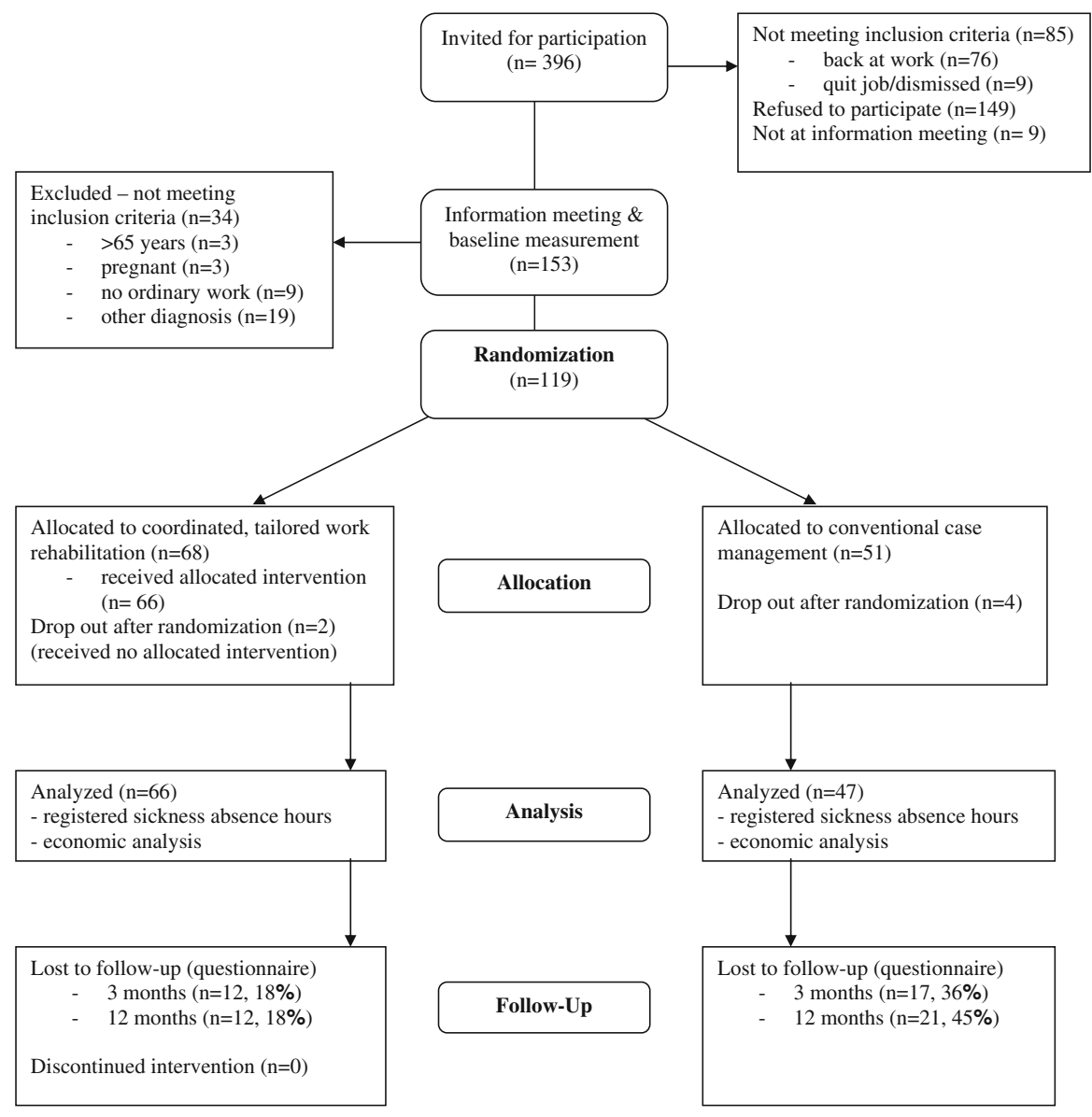


assessment and received a coordinated, tailored, and action-oriented RTW plan (see Participant flow diagram, Fig. 1). Administrative data on sickness absence hours, work status, and health care utilization were available for all participants $(n=113)$.

A questionnaire was sent 3 and 12 months after randomization; in the CTWR group, the questionnaire was completed and returned by $82 \%$ of the participants at both follow-up's compared to return rates of 64 and 55\% in CCM controls. A non-response analysis revealed that nonrespondents in both groups and at both time points were more likely to be men. Moreover, in the CTWR group, non-respondents at 3 month follow-up tended to have less vocationally education and more sickness absence hours.
Otherwise, non-respondents in both groups did not differ significantly from respondents with respect to other sociodemographic, health status, and work absence variables tested at 3 and 12 months follow-up.

\section{Baseline Characteristics}

Table 1 shows the patient characteristics and the values of the secondary outcome measures for the CTWR and CCM groups and the total population at baseline. Only minor differences were observed between the CTWR and the CCM group. Except for neck pain, reported by $12 \%$ of the CTWR participants and by $28 \%$ of the CCM controls, no significant differences were found between the groups.
Table 1 Baseline characteristics of the coordinated, tailored work rehabilitation intervention (CTWR) group, the conventional case management control (CCM) group, and the total study population
$\mathrm{SD}$, standard deviation; BMI, body mass index

a A higher score means a higher level of pain

b A higher score means a lower level of functional disability

* $P<0.05$

\begin{tabular}{|c|c|c|c|}
\hline Baseline characteristics & $\begin{array}{l}\text { CTWR } \\
(n=66)\end{array}$ & $\begin{array}{l}\text { CCM } \\
(n=47)\end{array}$ & $\begin{array}{l}\text { Total } \\
(n=113)\end{array}$ \\
\hline \multicolumn{4}{|l|}{ Age in years } \\
\hline Mean (SD) & $44.2(10.8)$ & $42.9(11.9)$ & $43.7(11.3)$ \\
\hline \multicolumn{4}{|l|}{ Gender } \\
\hline Males, $n(\%)$ & $34(51.5)$ & $17(36.2)$ & $51(45.1)$ \\
\hline $\begin{array}{l}\text { Duration of sickness absence prior } \\
\text { to inclusion, mean (SD) }\end{array}$ & $38.1(18.7)$ & $41.0(23.9)$ & $39.3(20.9)$ \\
\hline Median & 35.5 & 33 & 34 \\
\hline \multicolumn{4}{|l|}{ Education, $n(\%)$} \\
\hline$\leq 7$ years & $3(4.5)$ & $6(12.8)$ & $9(8.0)$ \\
\hline $8-9$ years & $26(39.4)$ & $17(36.2)$ & $43(38.1)$ \\
\hline 10 years & $16(24.2)$ & $17(36.2)$ & $33(29.2)$ \\
\hline$>10$ years & $20(30.3)$ & 7 (14.9) & $27(23.9)$ \\
\hline Under education & $1(1.5)$ & - & $1(0.9)$ \\
\hline \multicolumn{4}{|l|}{ BMI } \\
\hline Mean (SD) & $26.6(6.3)$ & $26.2(4.9)$ & $26.4(5.8)$ \\
\hline \multicolumn{4}{|l|}{ Job group, $n(\%)$} \\
\hline White collar & $34(51.5)$ & $20(42.6)$ & $54(47.8)$ \\
\hline Blue collar, skilled & $12(18.2)$ & $7(14.9)$ & $19(16.8)$ \\
\hline Blue collar, unskilled & $14(21.2)$ & $18(38.3)$ & $32(28.3)$ \\
\hline Self-employed & $5(7.6)$ & $1(2.1)$ & $6(5.3)$ \\
\hline Other & $1(1.5)$ & $1(2.1)$ & $2(1.8)$ \\
\hline Job satisfaction $(0-10)$, mean (SD) & $7.52(3.1)$ & $7.43(2.6)$ & $7.48(2.9)$ \\
\hline \multicolumn{4}{|l|}{ Pain sites (self-reported), $n(\%)$} \\
\hline Neck* & $8(12.1)$ & $13(27.7)$ & 21(18.6) \\
\hline Back, upper part & $10(15.2)$ & $4(8.5)$ & $14(12.4)$ \\
\hline Shoulder & $19(28.8)$ & $16(34.0)$ & $35(31.0)$ \\
\hline Back, lower part & $56(84.8)$ & $40(85.1)$ & $96(85.0)$ \\
\hline Lower extremities & $29(43.9)$ & $24(51.1)$ & $53(46.9)$ \\
\hline Lower extremities (under knee) & $23(34.8)$ & $13(27.7)$ & $36(31.9)$ \\
\hline \multicolumn{4}{|l|}{ Pain intensity $(0-10)^{\mathrm{a}}$, mean $(\mathrm{SD})$} \\
\hline Last week & $5.77(2.8)$ & $6.04(2.0)$ & $5.88(2.5)$ \\
\hline Last month & $6.56(2.0)$ & $6.96(1.9)$ & $6.73(2.0)$ \\
\hline Functional disability $(0-100)^{\mathrm{b}}$, mean $(\mathrm{SD})$ & $65.94(14.8)$ & $66.21(14.7)$ & $66.05(14.7)$ \\
\hline
\end{tabular}


Primary Outcome: Registered Sickness Absence Hours

Table 2 presents cumulative sickness absence hours for the five time intervals during the 12 months follow-up period. In the first 3 months following baseline and from 3 to 6 months, CTWR participants had fewer sickness absence hours than CCM controls; these differences were not statistically significant. For the time intervals 0-6 months, 6-12 months, and the entire follow-up period (0-12 months), the number of sickness absence hours was significantly lower in the CTWR group compared to the CCM controls.

Table 2 Register-based cumulative sickness absence hours during follow-up for CTWR intervention and CCM control group

\begin{tabular}{llll}
\hline $\begin{array}{l}\text { Sickness absence hours } \\
\text { (cumulative) }\end{array}$ & $\begin{array}{l}\text { CTWR } \\
(n=66)\end{array}$ & $\begin{array}{l}\text { CCM } \\
(n=47)\end{array}$ & $P^{*}$ \\
\hline 0-3 months & & & \\
$\quad \begin{array}{l}\text { Mean (SD) } \\
\text { Median }\end{array}$ & $278.3(165.9)$ & $331.1(152.9)$ & 0.060 \\
3-6 months & 262 & 335 & \\
$\quad$ Mean (SD) & $187.6(183.1)$ & $254.5(199.0)$ & 0.096 \\
$\quad$ Median & 134 & 234 & \\
6-12 months & & & \\
$\quad$ Mean (SD) & $190.4(312.1)$ & $411.7(423.1)$ & 0.009 \\
$\quad$ Median & 2.5 & 254 & \\
0-6 months & & $585.6(322.6)$ & 0.034 \\
Mean (SD) & $465.9(319.3)$ & 537 & \\
Median & 419 & & \\
0-12 month & & $997.3(668.8)$ & 0.006 \\
Mean (SD) & $656.6(565.2)$ & & \\
Median & 476 & & \\
\hline
\end{tabular}

SD, Standard deviation

* $P$ value for Mann Whitney $U$ test
Secondary Outcomes: Work Status, Pain Intensity, and Functional Disability

\section{Work Status}

On average, $42 \%$ of all participants had returned to work at 3 months follow-up: $45 \%$ in the CTWR group and $37 \%$ in the CCM control group. At 6 months follow-up, $69 \%$ had returned to work in the CTWR group compared to $48 \%$ in the control group. After 1 year, $71 \%$ of all participants had returned to work: $78 \%$ in the CTWR group and $62 \%$ in the control group. The percentages of those participants on part-time sick leave at 3, 6, and 12 months were 22, 13, and $9 \%$ in the CTWR group compared to 17,13 , and $7 \%$ in the control group. For full-time sick leave these percentages were 33,19, and 14\% in the CTWR group and 46, 39 and $31 \%$ in the control group, respectively.

\section{Pain intensity and Functional Disability}

Table 3 shows mean improvements and mean differences for pain intensity and functional disability at 3 and 12 month follow-up. Because of loss-to-follow-up and missing values, data was available for $n=54$ CTWR participants and $n=30$ (26) CCM controls. During the 3 and 12 months follow-up from baseline, pain intensity scores decreased significantly within both groups, whereas the scores for functional disability increased significantly within both groups (apart from functional disability in the CCM group at 3 month follow-up). With the exception of pain intensity at 3 months, we found no significant differences between the CTWR group and the CCM controls.

Initiatives and Actions for RTW During the First 3 Months of Follow-up

Table 4 shows that support/help from the work supervisor, roundtable discussions, workplace accommodations and/or

Table 3 Pain intensity and functional disability at 3 and 12 months follow-up, mean improvements within the CTWR and CCM groups and mean differences between groups

\begin{tabular}{|c|c|c|c|c|c|c|}
\hline & \multicolumn{3}{|c|}{3 Months follow-up } & \multicolumn{3}{|c|}{12 Months follow-up } \\
\hline & $n$ & $\begin{array}{l}\text { Mean } \\
\text { improvement (SD) }\end{array}$ & $\begin{array}{l}\text { Mean } \\
\text { difference }(95 \% \mathrm{CI})\end{array}$ & $n$ & $\begin{array}{l}\text { Mean } \\
\text { improvement (SD) }\end{array}$ & $\begin{array}{l}\text { Mean } \\
\text { difference }(95 \% \mathrm{CI})\end{array}$ \\
\hline \multicolumn{7}{|c|}{ Pain intensity last month } \\
\hline CTWR & 54 & $-2.91(2.6)$ & $1.64(0.47,2.81)$ & 54 & $-3.59(2.2)$ & $1.13(-0.11,2.38)$ \\
\hline $\mathrm{CCM}$ & 30 & $-1.27(2.6)$ & & 26 & $-2.46(3.3)$ & \\
\hline \multicolumn{7}{|c|}{ Functional disability } \\
\hline CTWR & 54 & $9.14(15.7)$ & $-5.83(-12.46,0.79)$ & 54 & $16.23(15.0)$ & $-7.27(-15.01,0.46)$ \\
\hline $\mathrm{CCM}$ & 30 & $3.30(12.5)$ & & 30 & $8.96(20.4)$ & \\
\hline
\end{tabular}

CTWR, coordinated, tailored work rehabilitation; CCM, conventional case management; SD, standard deviation; CI, confidence interval 
Table 4 Self-reported RTW initiatives and actions during the 3 months following baseline by CTWR and CCM group

CTWR, coordinated, tailored work rehabilitation: $n$ varies per item between $n=49$ and $n=52 ;$ CCM, conventional case management: $n$ varies between $n=28$ and $n=29$ $* P<0.05$

\begin{tabular}{lll}
\hline I have been seen by/I have received & CTWR (\%) & CCM (\%) \\
\hline Seen by general practitioner & 65 & 69 \\
Treatment/training by physiotherapist & 64 & 66 \\
Treatment/training by chiropractor & 23 & 17 \\
Seen a psychologist* & 31 & 3 \\
Treatment by alternative therapist & 17 & 21 \\
Workplace accommodations/job modifications* & 38 & 7 \\
Treatment or rehabilitation in the hospital setting & 28 & 31 \\
Roundtable discussions* & 45 & 17 \\
Support/help from the municipal social worker & 65 & 52 \\
Support/help from the labor union & 29 & 25 \\
Support/help from the supervisor at work* & 57 & 29 \\
Support/help from the colleagues at work & 62 & 54
\end{tabular}

Table 5 Economic evaluation: estimated costs for the CCM and CTWR groups and incremental costs (net benefit) at 6 and 12 months follow-up

\begin{tabular}{lccc}
\hline & $\begin{array}{l}\text { Estimated costs in the CCM } \\
\text { group in DKK (US \$) }\end{array}$ & $\begin{array}{l}\text { Estimated costs in the CTWR } \\
\text { group in DKK (US \$) }\end{array}$ & $\begin{array}{c}\text { Incremental costs } \\
\text { in DKK (US \$) }\end{array}$ \\
\hline 6 months follow-up & & & $12,000(2,200)$ \\
Intervention costs & 0 & $12,000(2,200)$ & $-19,097(-3,462)^{\mathrm{a}}$ \\
Average productivity loss & $128,726(23,335)$ & $109,629(19,873)$ & $-573(-104)^{\mathrm{b}}$ \\
Average outpatient treatment costs & $5,331(966)$ & $4,758(863)$ & $-7,670(-1,366)$ \\
Total incremental costs (net benefit) & & & $12,000(2,200)$ \\
12 months follow-up & 0 & $153,461(27,823)$ & $-67.375(-12,214)^{\mathrm{c}}$ \\
Intervention costs & $220,836(40.039)$ & $6,184(1,121)$ & $-3,598(-652)^{\mathrm{d}}$ \\
Average productivity loss & $9,782(1,773)$ & & $-58,973(-10,666)$ \\
Average outpatient treatment costs & & & \\
Total incremental costs (net benefit) & & & $12,200)$ \\
\hline
\end{tabular}

CCM, conventional case management; CTWR, coordinated, tailored work rehabilitation; Production per hour valued as gross wage per hour (for sickness absence hours see Table 2); 2006 price level; DKK converted into US \$ Aug. 2007. Negative incremental costs indicate positive net benefit to society

${ }^{\text {a }} P=0.034$ (Wilcoxon test)

${ }^{\text {b } P}=0.0195$ (Wilcoxon test). For inpatient treatment, treatment in the primary care sector and use prescribed medicine there were no significant differences between the CCM and CTWR groups

${ }^{c} P=0.006$ (Wilcoxon test)

${ }^{\mathrm{d}} P=0.047$ (Wilcoxon test). For inpatient treatment, treatment in the primary care sector and use prescribed medicine there were no significant differences between the CCM and CTWR groups

job modifications, and having been seen by a psychologist, were reported more often by the CTWR participants. With regard to the other RTW activities, no significant differences between CTWR participants and CCM controls were found.

\section{Economic Evaluation}

Based on the accounts analysis from the interdisciplinary team, the average direct intervention costs for CTWR participants were estimated around Denmark Kroner (DKK) 12,000 (approx. US \$ 2,200) per person, i.e., incremental costs compared to the CCM controls (note: monetary units were in 2006 DKK/US \$ using the exchange rate from 2007). As shown in Table 5, there was a difference in productivity loss at 6 and 12 months followup. At 6 months follow-up, the total reduced productivity loss in CTWR participants as compared to CCM controls was estimated DKK 19,047 (approx. US \$ 3,462) due to fewer sickness absence hours (see Table 2). At 12 months follow-up, the total reduced production loss in CTWR participants was estimated DKK 67,375 (approx. US \$ 12,214) compared to CCM controls.

During the entire 12 months follow-up period, CTWR participants had fewer primary health care (83 vs. $87 \%$ ) and outpatient contacts (46 vs. 53\%), had fewer 
hospitalizations (20 vs. $23 \%$ ), and used more prescribed medicine (74 vs. 64\%) compared to controls. Regarding health care utilization costs, we found no significant differences between CTWR participants and CCM controls with the exception of outpatient treatment: DKK 6,184 (approx. US \$1,121) in CTWR participants compared to DKK 9,782 (approx. US \$ 1,773) in CCM controls $(P=0.047$; see Table 5). Adding this cost difference to the above results, societal savings were even higher after 12 months (Table 5). Overall, the net benefit of CTWR after 6 months was approximately DKK 7,670 (approx. US $\$ 1,366)$, i.e., the average difference in productivity loss minus direct intervention costs per person and incremental cost savings in outpatient treatment. At 12 months followup, the net benefit was approximately DKK 58,973 (approx. US \$ 10,666) per person.

In Table 6, the costs per averted absence day are presented for CTWR compared to CCM (cost-effectiveness analysis). In these analyses, reduced productivity loss is not included. At 6 months follow-up, the cost-effectiveness ratio is DKK 705 per averted absence day (approx. US \$ 129.40 per day); at 12 months follow-up, the ratio is DKK 183 per averted absence day (approx. US $\$ 33.70$ per day).

As shown in Table 5 and 6, the net benefit at 12 months follow-up was noticeably higher when compared to 6 months follow-up. Table 7 presents the results from one- way sensitivity analyses. Intervention costs and wage reduction were chosen for testing as they can be readily calculable and are key indices for both the individual and the health care system. Even with increased intervention costs $(+100 \%)$ or reduced wages $(-25 \%)$ CTWR was still associated with cost savings at 12 months follow-up. At 3 months follow-up, the costs saved (CTWR compared to CCM) were small and non-significant (DKK 3,277 (US \$ 594)).

\section{Discussion}

In the present study the effect of CTWR provided by an interdisciplinary team to workers on sick leave due to MSDs was compared to conventional case management. Sickness absence hours during follow-up, intervention costs, productivity loss, and health care utilization costs were evaluated. The findings suggest that CTWR participants had fewer sickness absence hours during follow-up compared to CCM controls, particularly in the second half year of the follow-up period. Moreover, the economic evaluation suggests a difference in productivity loss at 6 and 12 months in favor of the CTWR participants. With regard to health care utilization costs, the study showed a significant difference between CTWR and CCM for

Table 6 Economic evaluation: cost-effectiveness analysis

\begin{tabular}{llll}
\hline & $\begin{array}{l}\text { Incremental costs } \\
\text { in DKK (US \$) }\end{array}$ & $\begin{array}{l}\text { Average averted } \\
\text { absence days }\end{array}$ & $\begin{array}{l}\text { Cost-effectiveness ratio (costs per } \\
\text { averted absence day), DKK/day (US \$/day) }\end{array}$ \\
\hline $\begin{array}{l}\text { b months follow-up } \\
\text { CTWR vs. CCM group }\end{array}$ & $11,427(2,096)$ & 16.2 & $705(129.4)$ \\
$\begin{array}{l}12 \text { months follow-up } \\
\text { CTWR vs. CCM group }\end{array}$ & $8,402(1,548)$ & 46.0 & $183(33.7)$ \\
\hline
\end{tabular}

CCM, conventional case management; CTWR, coordinated, tailored work rehabilitation; 2006 price level; DKK converted into US \$ Aug. 2007

${ }^{\mathrm{a}}$ Here incremental costs are intervention cost + average treatment costs at outpatient clinics (see Table 5)

b Average averted absence days were calculated on the basis of the difference in cumulative sickness absence hours between the two groups (see Table 2). About $7.4 \mathrm{~h}$ equal 1 day

Table 7 Economic evaluation: sensitivity analysis

\begin{tabular}{|c|c|c|c|}
\hline & $\begin{array}{l}\text { Estimated costs in the CCM } \\
\text { group in DKK (US \$) }\end{array}$ & $\begin{array}{l}\text { Estimated costs in the CTWR } \\
\text { group in DKK (US \$) }\end{array}$ & $\begin{array}{l}\text { Incremental costs (net } \\
\text { benefit) in DKK (US \$) }\end{array}$ \\
\hline $\begin{array}{l}\text { Total incremental costs, } 12 \text { months follow-up (see } \\
\text { Table 5) }\end{array}$ & & & $-58,973(-10,666)$ \\
\hline Higher intervention costs ( $100 \%$ increase) & $230,618(41,811)$ & $183,645(33,294)$ & $-46,973(-8,516)$ \\
\hline Reduction in the applied wages ( $25 \%$ reduction) & $186,451(33,803)$ & $140,953(25,554)$ & $-45,498(-8,249)$ \\
\hline At 3 months follow-up & $102,981(18,670)$ & $99,704(18,076)$ & $-3,277^{\mathrm{a}}(-594)$ \\
\hline
\end{tabular}

CCM, conventional case management; CTWR, coordinated, tailored work rehabilitation; Production per hour valued as gross wage per hour (for sickness absence hours see Table 2); 2006 price level; DKK converted into US \$ Aug. 2007. Negative incremental costs indicate positive net benefit to society

${ }^{\text {a }}$ Difference significant at $10 \%$ level 
outpatient treatment, but not for primary health care contacts, hospitalization, and prescribed medication.

The main components of this CTWR project were the multidisciplinary assessment and the subsequent interdisciplinary team conference with the development of a coordinated, tailored, and action-oriented RTW plan in close consultation with relevant stakeholders. Høgelund and Holm [21] report that in Denmark the municipal case manager's responsibility has increased. However, it is not known if conventional case management increases the RTW of sick-listed workers with MSDs. As compared to CCM controls, CTWR participants reported that they more often saw a psychologist, took part in roundtable discussions, received workplace accommodations/job modifications and received help/support from their daily supervisor. These supplementary RTW initiatives and actions were probably facilitated by the interdisciplinary team. Whether these RTW activities, independently or combined, further reduced sickness absence hours has to be determined in future research. In line with the work by Durand et al. [15], we have to describe the exact CTWR mechanisms that reduce sickness absence hours and increase a sustainable RTW.

Our study provides suggestive evidence for a beneficial effect of CTWR, i.e., reduced sickness absence hours during follow-up. CTWR seems to be cost saving for society. This project demonstrated economic gains with reduced productivity loss due to fewer sickness absence hours that were greater than the direct intervention costs. These findings should, however, be confirmed in different settings. Although different administrative/jurisdictional settings, project components, designs, definitions, and outcome measurements hinder a direct comparison, mixed results were found in two Swedish studies. One study examined the effects of co-financed interdisciplinary teamwork on sick leave for people with MSDs [29]. Hultberg et al. [29] found no effect of health care centres with a co-financing model and a structure for team collaboration on reduced numbers of sick leave days. The other study looked at work resumption in association with vocational rehabilitation [30]. Karrholm et al. [30] showed that individuals, who received coordinated rehabilitation based on systematic multi-professional co-operation, had more working days after the intervention period than those with conventional rehabilitation. This effect was only found in those with long-term sickness absence. In Canada, Loisel et al. [17] performed a cost-benefit and cost-effectiveness analysis of a disability prevention model for back pain management. At one year follow-up, the authors estimated the costs per saved day on full benefit (DFB) for the Sherbrooke model at 213.50 CAD \$ per DFB. In our study, we estimated the costs per averted absence day at 33.70 US \$ per day at 12 months follow-up. An explanation for this clear difference might be that the CTWR intervention averted on the average 46 absence days compared to CCM, whereas the Sherbrooke model saved 11 days on full benefit compared to standard care.

The strength of our study is the robust design with record linkages to three national registries. This provided the basis for the analyses of sickness absence and economic evaluations of productivity loss and health care utilization. The administrative sickness absence data were derived from the Danish National Health Insurance Service Registry. These data as well as the data from other national registries are deemed to be reliable and accurate. Moreover, record linkage provided complete administrative data during follow-up, which further strengthened our findings and made analyses of non-respondents and loss-to-followup possible. We used cumulative sickness absence hours during follow-up as our primary outcome instead of a one time measure of work status (RTW yes/no) or time to first RTW. This gives a more precise picture of work disability (including part-time sickness absence and/or recurrences of work absence) during follow-up [31]. Cumulative sickness absence hours were also used in the estimation of productivity loss in the CTWR and CCM groups. We applied the human capital approach, i.e., production per hour was valued as the gross wage per hour (including employment overhead and benefits). An alternative approach is the friction cost approach in which productivity loss only occurs in the friction period (see e.g., Sculpher [32]). In general, the friction cost approach leads to lower estimates of productivity loss compared to the human capital approach. The friction cost approach requires more information and/or assumptions than the human capital approach in order to estimate parameters (e.g., the duration of the friction period). Because the time window in our study was only 12 months, one may argue that the estimates based on the human capital approach or the friction cost approach would not be markedly different. Moreover, in the sickness absence registration (and the estimation of productivity loss) part-time sick leave was taken into account. In terms of productivity, no additional data was available. Thus it was assumed that productivity per work hour was the same before and after the sick leave.

We applied a societal perspective, i.e., key costs and effects were included. This only holds to a certain extent because the benefits/health effects of the intervention were incorporated into the differences in productivity costs. In this approach only working hours were valued. Other types of benefits/effects (e.g., better ability to engage in leisure activities) were not included in the productivity costs and were not valued.

Productivity loss, as shown in Table 5, represents the loss to society in the CTWR and CCM groups. However, the total loss to society encompasses employees, 
employers, and the public sector. The financial loss for the employee depends on the sickness absence policies and practices of the employer. For instance, if the employee receives his/her full wage during the entire sickness absence period, then there will be no financial loss for the employee. There will always be a loss for the employer. In the first 2 weeks of sickness absence, the loss corresponds to the gross wage. After 2 weeks of absence, the maximum unemployment benefit is refunded to the employer, reducing the employer's loss. With respect to the public sector, after 2 weeks of sickness absence there will be a loss that corresponds to the maximum unemployment benefit. An additional loss to the public sector is reduced tax income.

A limitation of the present study is that the required sample size was not obtained due to recruitment problems within the inclusion period. "Lasagna's Law" i.e., the observation that when trial recruitment starts, the supply of suitable patients becomes a fraction of what it was assumed to be before the trial began, [33], apparently can be applied to this study. We do not have an explanation for this as the pilot study suggested a sufficient supply of suitable subjects. In spite of fewer subjects, we were able to include and randomize enough participants to conduct the registerbased analyses. With respect to baseline comparability, CCM controls were more likely to be female, to be less educated, and to report neck pain. We can not rule out that this difference might have influenced the results and further research is warranted. Another issue concerns the loss-tofollow-up for the self-reported secondary outcome measures of pain intensity and functional disability, in particular in CCM controls. This raises the question of selective participation, which may have biased the results. A non-response analysis showed that non-respondents were more likely to be men-in both groups and at both measurement points. In the CTWR group, non-respondents at 3 months follow-up were more likely to have less vocational education and more sickness absence hours. Nonrespondents and respondents were similar with respect to all other socio-demographic and health status variables as well as sickness absence hours at the 12 months follow-up. Another issue pertains to the secondary outcome measure functional disability, which was assessed with the Oswestry LBP Disability Questionnaire. In our study, some workers with other types of MSD were included, which might have influenced the results. However, in both groups, CTWR and CCM, $85 \%$ of the workers reported LBP. Many of the Oswestry questions are quite general and probably can be used for general MSDs. However, the questions have not been validated for this broader group. In all, pain intensity and functional disability results should be interpreted with caution. However, they are corroborated by administrative sickness absence data.
Furthermore, when interpreting our results, the following issues should be considered. It was not possible to "blind" participants and interdisciplinary team members for the allocated "intervention". However, as all participants received the follow-up questionnaires at home, a direct influence by the researchers or the team members seems unlikely regarding questionnaire data. Another question relates to the contrast between CTWR participants and CCM controls during follow-up. Health care utilization in both groups was mapped in an objective way with national registry data. In addition, participants provided information on the RTW initiatives and actions during the first 3 months. However, more frequent measurements during a longer follow-up period would have been desirable to further understand the complex RTW process. With respect to generalizability and implementation of our findings, caution is suggested. Direct translation to other settings, diagnoses, and jurisdictional contexts might be difficult and should be explored in future research.

In conclusion, the findings of this pragmatic randomized trial provide suggestive evidence that CTWR employed by an interdisciplinary team is effective compared to conventional case management in workers absent from work due to MSDs. Workers, who underwent CTWR had fewer sickness absence hours than CCM controls, particularly in the second half-year of follow-up. The economic evaluation showed that-in terms of productivity loss-CTWR seems to be cost saving for the society. Further research is needed to explore in more detail the processes and mechanisms of CTWR by interdisciplinary teams in order to advocate safe, healthy, and sustainable RTW.

Acknowledgments The study was funded by grants of the Danish National Labor Market Authority, Vejle County, and the Danish Chiropractic Research Fund.

Ethical Approval The study has been registered by Datatilsynet (the Danish Data Protection Agency). According to The Regional Committee on Biomedical Research Ethics, Vejle and Funen (part of The Danish National Committee on Biomedical Research Ethics), ethical approval was not required for this study. The trial has been registered with ClinicalTrials.gov (NCT 00463216).

Conflict of Interest Kilsgaard is now the director of KIApro, an organization that develops and implements systematic programs for work rehabilitation in municipalities in Denmark. The present study was planned, designed and performed while Kilsgaard was working at the Department of Development and Labor Market of Vejle County. The pre-arranged sickness absence and economic evaluations of the study were conducted by researchers from the National Centre for the Working Environment in Copenhagen and the Centre for Applied Health Services Research and Technology Assessment, University of Southern Denmark in Odense. The researchers and other project group members have no competing interests related to this study, i.e., no financial and personal relationships that could be viewed as potential conflict of interest. 
Open Access This article is distributed under the terms of the Creative Commons Attribution Noncommercial License which permits any noncommercial use, distribution, and reproduction in any medium, provided the original author(s) and source are credited.

\section{References}

1. Gjesdal S, Bratberg E. Diagnosis and duration of sickness absence as predictors for disability pension: results from a threeyear, multi-register based and prospective study. Scand J Public Health. 2003;31(4):246-54. doi:10.1080/14034940210165154.

2. Gjesdal S, Lie RT, Maeland JG. Variations in the risk of disability pension in Norway 1970-1999. A gender-specific ageperiod-cohort analysis. Scand J Public Health. 2004;32(5):340-8. doi: 10.1080/14034940410029487.

3. Kivimaki M, Forma P, Wikstrom J, Halmeenmaki T, Pentti J, Elovainio M, et al. Sickness absence as a risk marker of future disability pension: the 10-town study. J Epidemiol Community Health. 2004;58(8):710-1. doi:10.1136/jech.2003.015842.

4. Labriola M, Lund T. Self-reported sickness absence as a risk marker of future disability pension. Prospective findings from the DWECS/DREAM study 1990-2004. Int J Med Sci. 2007;4(3): 153-8.

5. Lund T, Kivimaki M, Labriola M, Villadsen E, Christensen KB. Using administrative sickness absence data as a marker of future disability pension: the prospective DREAM study of Danish private sector employees. Occup Environ Med. 2008;65(1):2831. doi:10.1136/oem.2006.031393.

6. Beskæftigelsesministeriet (The Danish Ministry of Employment). Analyse af sygefraværet (analysis of sickness absence). Copenhagen: Ministry of Employment; 2008.

7. Loisel P, Durand M-J, Berthelette D, Vezina N, Baril R, Gagnon $\mathrm{D}$, et al. Disability prevention-new paradigm for the management of occupational back pain. Dis Manage Health Outcomes. 2001;9(7):351-60. doi:10.2165/00115677-200109070-00001.

8. Frank J, Sinclair S, Hogg-Johnson S, Shannon H, Bombardier C, Beaton D, et al. Preventing disability from work-related low-back pain. New evidence gives new hope-if we can just get all the players onside. Can Med Assoc J. 1998;158(12):1625-31.

9. Briand C, Durand MJ, St-Arnaud L, Corbiere M. How well do return-to-work interventions for musculoskeletal conditions address the multicausality of work disability? J Occup Rehabil. 2008;18(2):207-17. doi:10.1007/s10926-008-9128-1.

10. Franche RL, Cullen K, Clarke J, Irvin E, Sinclair S, Frank J. Workplace-based return-to-work interventions: a systematic review of the quantitative literature. J Occup Rehabil. 2005;15(4):607-31. doi:10.1007/s10926-005-8038-8.

11. Krause N, Frank JW, Dasinger LK, Sullivan TJ, Sinclair SJ. Determinants of duration of disability and return-to-work after work-related injury and illness: challenges for future research. Am J Ind Med. 2001;40(4):464-84. doi:10.1002/ajim.1116.

12. Krause N, Dasinger LK, Deegan LJ, Rudolph L, Brand RJ. Psychosocial job factors and return-to-work after compensated low back injury: a disability phase-specific analysis. Am J Ind Med. 2001;40(4):374-92. doi:10.1002/ajim.1112.

13. Waddell G. Preventing incapacity in people with musculoskeletal disorders. Br Med Bull. 2006;77-78:55-69. doi:10.1093/bmb/ $1 \mathrm{~d} 1008$.

14. Hansson TH, Hansson EK. The effects of common medical interventions on pain, back function, and work resumption in patients with chronic low back pain: a prospective 2-year cohort study in six countries. Spine. 2000;25(23):3055-64. doi:10.1097/ 00007632-200012010-00013.
15. Durand MJ, Vachon B, Loisel P, Berthelette D. Constructing the program impact theory for an evidence-based work rehabilitation program for workers with low back pain. Work. 2003;21(3):23342.

16. Loisel P, Abenhaim L, Durand P, Esdaile JM, Suissa S, Gosselin $\mathrm{L}$, et al. A population-based, randomized clinical trial on back pain management. Spine. 1997;22(24):2911-8. doi:10.1097/ 00007632-199712150-00014.

17. Loisel P, Lemaire J, Poitras S, Durand MJ, Champagne F, Stock $\mathrm{S}$, et al. Cost-benefit and cost-effectiveness analysis of a disability prevention model for back pain management: a six year follow up study. Occup Environ Med. 2002;59(12):807-15. doi:10.1136/ oem.59.12.807.

18. Anema JR, Steenstra IA, Bongers PM, de Vet HC, Knol DL, Loisel P, et al. Multidisciplinary rehabilitation for subacute low back pain: graded activity or workplace intervention or both? A randomized controlled trial. Spine. 2007;32(3):291-8. doi: 10.1097/01.brs.0000253604.90039.ad.

19. Steenstra IA, Anema JR, van Tulder MW, Bongers PM, de Vet HC, Van Mechelen W. Economic evaluation of a multi-stage return to work program for workers on sick-leave due to low back pain. J Occup Rehabil. 2006;16(4):557-78. doi:10.1007/s10926006-9053-0.

20. Steenstra IA, Anema JR, Bongers PM, de Vet HC, Van Mechelen W. Cost effectiveness of a multi-stage return to work program for workers on sick leave due to low back pain, design of a population based controlled trial. BMC Musculoskelet Disord. 2003;4(1):26. doi:10.1186/1471-2474-4-26. (ISRCTN60233560).

21. Hogelund J, Holm A. Case management interviews and the return to work of disabled employees. J Health Econ. 2006;25(3):50019. doi:10.1016/j.jhealeco.2005.07.007.

22. Durand MJ, Loisel P, Hong QN, Charpentier N. Helping clinicians in work disability prevention: the work disability diagnosis interview. J Occup Rehabil. 2002;12(3):191-204. doi:10.1023/A: 1016846712499.

23. Waddell G, Burton AK. Concepts of rehabilitation for the management of low back pain. Best Pract Res Clin Rheumatol. 2005;19(4):655-70. doi:10.1016/j.berh.2005.03.008.

24. Franche RL, Krause N. Readiness for return to work following injury or illness: conceptualizing the interpersonal impact of health care, workplace, and insurance factors. J Occup Rehabil. 2002;12(4):233-56. doi:10.1023/A:1020270407044.

25. Bandura A. Self-efficacy: toward a unifying theory of behavioral change. Psychol Rev. 1977;84(2):191-215. doi:10.1037/0033295X.84.2.191.

26. Linton SJ, Boersma K. Early identification of patients at risk of developing a persistent back problem: the predictive validity of the Orebro musculoskeletal pain questionnaire. Clin J Pain. 2003;19(2):80-6. doi:10.1097/00002508-200303000-00002.

27. Lauridsen HH, Hartvigsen J, Manniche C, Korsholm L, GrunnetNilsson N. Danish version of the Oswestry disability index for patients with low back pain. Part 1: cross-cultural adaptation, reliability and validity in two different populations. Eur Spine J. 2006;15(11):1705-16. doi:10.1007/s00586-006-0117-9.

28. Lauridsen HH, Hartvigsen J, Manniche C, Korsholm L, GrunnetNilsson N. Danish version of the Oswestry disability index for patients with low back pain. Part 2: sensitivity, specificity and clinically significant improvement in two low back pain populations. Eur Spine J. 2006;15(11):1717-28. doi:10.1007/s00586006-0128-6.

29. Hultberg EL, Lonnroth K, Allebeck P, Hensing G. Effects of cofinanced interdisciplinary teamwork on sick leave for people with musculoskeletal disorders. Work. 2006;26(4):369-77.

30. Karrholm J, Ekholm K, Jakobsson B, Ekholm J, Bergroth A, Schuldt K. Effects on work resumption of a co-operation project in vocational rehabilitation. Systematic, multi-professional, 
client-centred and solution-oriented co-operation. Disabil Rehabil. 2006;28(7):457-67. doi:10.1080/09638280500198063.

31. Krause N, Dasinger LK, Deegan LJ, Brand RJ, Rudolph L. Alternative approaches for measuring duration of work disability after low back injury based on administrative workers' compensation data. Am J Ind Med. 1999;35(6):604-18. doi:10.1002/ (SICI)1097-0274(199906)35:6<604::AID-AJIM8>3.0.CO;2-T.
32. Sculpher M. The role and estimation of productivity cost in economic evaluation. In: Drummond $\mathrm{M}$, Mc Guire A, editors. Economic evaluation in health care: merging theory with practice. Oxford University Press: New York; 2001.

33. Gorringe JAL. Initial preparation for clinical trials. In: Harris EL, Fitzgerald JD, editors. The principles and practice of clinical trials. Edinburgh: Livingstone; 1970. 